\title{
Inoculating Against Pro-Plagiarism Justifications: Rational and Affective Strategies
}

\author{
Josh Compton \& Michael Pfau
}

Student plagiarism continues to threaten academic integrity. This investigation assessed whether an inoculation message strategy could combat university plagiarism by protecting student attitudes against pro-plagiarism justification arguments. Additionally, we sought theoretical confirmation of previous findings on involvement and accessibility in inoculation, examined the effects on vested interest, and evaluated matching and mismatching strategies in terms of affect- and rationality-based inoculation treatment messages and subsequent attack messages. A total of 225 students participated in three sessions spanning six weeks. Results indicated that none of the inoculation treatments conferred resistance as measured in attitude toward plagiarism, but all treatments enhanced involvement and attitude accessibility, and the fear-and rationality-based treatments enhanced vested interest. Additionally, fear-based treatments derogated the source of the message. Results also suggest that a matching strategy is superior with both affect-and rationality-based attack messages, such that inoculation treatments are most effective when using the same argument bases (e.g., affective or rational) as the attack message. These results offer guidance for crafting communication campaign strategies to reduce the occurrence of student plagiarism offenses.

Keywords: Inoculation; Resistance to Influence; Plagiarism

Cognitive and affective factors keep many students from violating academic codes of conduct by plagiarizing their work. Love and Simmons (1998) found that students who resist the temptation to plagiarize do so for rational, cognitive reasons (such as fairness to original authors) and affect-based reasons (such as fear and anticipated

\footnotetext{
Josh Compton (Ph.D., University of Oklahoma, 2004) is Assistant Professor and Chair of the Department of Communication at Southwest Baptist University. Michael Pfau (Ph.D., University of Arizona, 1987) is Professor and Chair of the Department of Communication at the University of Oklahoma. Correspondence to: Josh Compton, Department of Communication, Southwest Baptist University, 1600 University Avenue, Bolivar, MO 65613, USA. Email: jcompton@sbuniv.edu.
} 
guilt avoidance). However, while many students resist temptation, plagiarism remains a continuing problem in higher education, with studies indicating that $40-90 \%$ of students cheat (Moeck, 2002). Seemingly, some students' cognitive and affective attitudes upholding academic integrity are not strong enough to withstand plagiarism justifications arising from internal pressures (e.g., temptation) and external pressures (e.g., academic demands).

This study assesses an inoculation strategy for helping students resist temptations to plagiarize. Confirmation of inoculation's efficacy would offer a preemptive strategy against a continuing problem in higher education. Further, the application of inoculation to the applied context of plagiarism prevention in academic settings answers a call by Compton and Pfau (2005) to extend inoculation to contexts that involve less conventional, explicit counterattitudinal messages.

\section{Plagiarism Problems in Higher Education}

Plagiarism is "appropriating someone else's words or ideas without acknowledgement" (Moulton \& Robinson, 2002, p. 1316). The word derives from the Latin plagiarus, or "kidnapper" (Hawley, 1984), alluding to a theft of ideas. While there are objective criteria for what constitutes plagiarism, the moral dimensions of plagiarism add to its complexity (Bennett, 2005). Recognizing the threat plagiarism poses to academic integrity, scholars have focused attention on plagiarism and its prevention, with over 100 published studies since the 1970s (Whitley \& Keith-Spiegel, 2002).

The moral dimensions of plagiarism suggest that culture impacts views on and practices of plagiarism and academic conduct. As examples, Roig and Caso (2005) found gender differences in uses of fraudulent excuses; Sutherland-Smith (2005) explored global and technological perspectives related to plagiarism and specifically examined the prevalent Western view of authorship; and Park (2003) compared North American research into plagiarism to the unique needs of UK institutions.

Results from recent investigations of academic misconduct are discouraging. Rutgers University professor Donald McCabe, with the Center for Academic Integrity at Duke University, found that, in the last year, 38\% of undergraduates had directly copied and pasted Internet content, passing it off as their original work (Cohen, 2003). Another investigation revealed that over $90 \%$ of students report their classmates "often," "very frequently," and "sometimes" plagiarize (Kellogg, 2002). Investigations suggest that teaching students what constitutes, and how to avoid, plagiarism is an effective deterrent (Landau, Druen, \& Arcuri, 2002), but caution that the efficacy of instructional tactics may not work as well when "a grade is at stake" (p. 115). While we agree with researchers who call for proactive measures to discourage plagiarism (Landau et al., 2002; Moeck, 2002), we believe that efforts to curb plagiarism should extend beyond mere instructional programs to encompass attitudinal and affective approaches. The inoculation construct seems a viable candidate for such a strategy. 


\section{The Inoculation Process of Conferring Resistance to Influence}

The inoculation process of conferring resistance to influence is built on a medical inoculation metaphor. According to McGuire's (1964) inoculation theory, individuals can be inoculated against persuasion, similarly to how individuals can be inoculated against viruses. A biological inoculation injects a weakened version of a virus or other offending agent to trigger resistance (e.g., antibodies) against future viral attacks. McGuire (1964) posited that an attitudinal resistance inoculation treatment warns the individual of a future attitudinal attack against an existing, yet vulnerable, attitude and then presents weakened counter-attitudinal arguments to build attitudinal resistance. The effectiveness of inoculative treatments in maintaining attitudes in the presence of counterattitudinal persuasive messages has been supported by laboratory experiments (e.g., Pfau et al., 2004, 2006) and successfully tested in applied settings such as political campaigns (An \& Pfau, 2004; Pfau \& Burgoon, 1988; Pfau, Kenski, Nitz, \& Sorenson, 1990), public relations (Burgoon, Pfau, \& Birk, 1995; Wan \& Pfau, 2004), and advertising (Compton \& Pfau, 2004; Pfau, 1992). In addition, the theory is supported by research in adolescent health-preventative contexts, including smoking (Pfau \& Van Bockern, 1994; Pfau, Van Bockern, \& Kang, 1992; Szabo \& Pfau, 2002) and drinking (Godbold \& Pfau, 2000). In laboratory studies and applied studies, the inoculation approach protects attitudes from subsequent attacks, conferring attitudinal resistance to those inoculated. With established efficacy in an array of contexts, this investigation predicts that inoculation treatment messages will unleash the process of resistance to discourage plagiarism:

$\mathrm{H1}$ : Inoculation messages confer attitudinal resistance to messages justifying plagiarism.

While the conventional explanation of threat generating arguments and refutations to those arguments has guided inoculation research since its inception, more recent investigations have explored other mechanisms that may be at work in the process of resistance. Two processes that have received attention are enhanced issue involvement and attitude accessibility.

During the 1990s, research investigated the impact of involvement as an independent variable, proposing that involvement may act as a precondition for inoculation (Pfau, 1992). Pfau, Tusing, Koerner, et al. (1997) conceptualized issue involvement as "the importance or salience of an attitude object for a receiver" (p. 190). This definition is consistent with Zaichkowsky's (1985) personal involvement construct, Johnson and Eagly's (1989) outcome-relevant involvement, and Petty and Cacioppo's (1979) issue involvement. Pfau, Tusing, Koerner, et al. (1997) found involvement to be a requisite for inoculation, arguing that involvement "holds the key to inoculation's terrain" (p. 210). Later research examined issue involvement as a dependent variable, discovering that inoculation treatments enhance base involvement levels, even after only one treatment message (Compton \& Pfau, 2004; Pfau 
et al., 2004). Inoculation is not only influenced by involvement, it also directly enhances involvement.

Pfau and colleagues (2003) found that inoculation messages unleash an active process that, in addition to generating the counterarguing process, also activates attitudinal nodes, enhancing attitude accessibility. This finding was confirmed in subsequent studies (Compton \& Pfau, 2004; Pfau et al., 2004). Collectively, these results suggest that attitude accessibility offers an alternative explanation for how inoculation confers resistance. Inoculation makes attitudes toward issues more accessible, or brought to the surface.

Although not previously examined in inoculation research, Crano's (1995) multifaceted concept of vested interest warrants consideration in inoculation research. Crano argued that stake (personal consequence to the individual), salience (degree of accessibility), certainty (assessment of consequences), immediacy (how soon the consequences will happen), and self-efficacy (assessment of one's ability to face challenges) - collectively-impact whether an attitude influences behavior. He termed this construct vested interest, which represents "the extent to which an attitude object is hedonically relevant for the attitude holder" (Crano, 1995, p. 131).

A single inoculation treatment has already been found to enhance involvement levels (Compton \& Pfau, 2004; Pfau et al., 2004) and increase attitude accessibility (Compton \& Pfau, 2004; Pfau et al., 2003Pfau et al., 2004). Involvement and attitude accessibility are critical components of the vested interest construct. This study posits that, for the same reason inoculation treatments enhance involvement and accessibility, inoculation treatment messages will also enhance vested interest.

H2: Inoculation treatment messages: (a) enhance base involvement levels; (b) elicit attitude accessibility; and (c) increase perception of vested interest when compared to controls.

\section{Source Derogation}

In the decade following the introduction of the inoculation strategy for conferring resistance, Tannenbaum and his colleagues offered source derogation as a successful preemptive strategy for conferring resistance. Tannenbaum's explanation was grounded in the congruity principle, and results indicated effectiveness comparative with inoculation treatments (Tannenbaum, 1967; Tannenbaum, Macaulay, \& Norris, 1966; Tannenbaum \& Norris, 1965). In these studies, the experimental "source attack" strategy provided explicit criticism of a source's credibility. For example, one source of an attack message was described as "incompetently staffed, riddled with political appointees, and generally not serving the public interest" (Tannenbaum, Macaulay, \& Norris, 1966, p. 234), while in another case the source was accused of "unethical and unprofessional behavior" (Tannenbaum \& Norris, 1965, p. 150).

Stone (1969) also tested the effectiveness of preemptive source derogation, comparing a source-derogation inoculation treatment condition with a messagederogation inoculation treatment. He posited that source-oriented individuals would 
be more influenced by source-derogation inoculation treatment messages and that message-oriented individuals would be more influenced by message-derogation inoculation treatment messages. While he found that both types of inoculation messages confer resistance, there was no difference between source- and messageoriented individuals.

Researchers have consistently found that inoculation treatments undermine the credibility of the source of subsequent attack messages (Pfau \& Burgoon, 1988; Pfau, Holbert, Zubric, Pasha, \& Lin, 2000; Pfau et al., 1990). Thus, we expect similar effects of inoculation in the context of plagiarism.

H3: Inoculation messages elicit derogation of the source of a subsequent proplagiarism message, with participants perceiving the source as (a) less competent, (b) of poorer character, and (c) of lower sociability when compared to those receiving no inoculation treatment (controls).

\section{Matched or Mismatched Approaches: Affective and Rational Messages}

Whether a persuasive attempt should match or not match the attitude underlying a position has been the subject of debate in attitudinal research (e.g., Dubé, Chattopadhyay, \& Letarte, 1996; Fabrigar \& Petty, 1999; Millar, 1992). This research looked at the effectiveness of persuasive appeals, and at issue was whether an attitude based on affect is more likely to be influenced by an affective-based or a cognitive-based persuasive message, and vice versa. Some investigations find a matching strategy to be more persuasive (e.g., Edwards, 1990) while others find support for the persuasiveness of a mismatching strategy (e.g., Millar \& Millar, 1990). Edwards' (1990) explanation for the superiority of matching is based on a functional approach to attitudes; Edwards argues that a matched strategy poses a direct challenge to the core attitude function, motivating the individual to resist attempts at influence. Millar and Millar (1990) explained that their mismatched strategy was based on making an attitudinal challenge less clearly recognizable. They argued that, with a matched strategy, the threat to an existing attitude is clearly recognizable, and participants are able to counterargue against the counterattitudinal message.

While Edwards (1990) and Millar and Millar's (1990) research explored attitudinal bases, their results have application to inoculation research. Inoculation treatment messages elicit threat to an attitude attack, thereby reducing the chance that one who is inoculated will be caught unaware by the persuasive attempt. The attitude attack can no longer "slip by" the individual. Without the "surprise attack," it is more likely that Edwards' (1990) matching explanation would apply to the inoculation process.

Two contemporary studies have examined the relative effectiveness of cognitivelybased and affect-based inoculation treatment messages. Lee and Pfau (1998) compared affect-based appeals (those using anecdotes and affect-laden counterarguments and refutations) and cognitively-based appeals (those using rational, evidence-based arguments and avoiding affect-laden language) in the face of 
affect-based and cognitively-based attack messages. As predicted, the cognitive treatments promoted the most resistance; these were successful against cognitive and positive-affect attacks, but not against negative-affect attacks. They also found that both affect-positive and affect-negative treatments conferred resistance to cognitive attacks, but not to affective attacks. These results do not support an overall matching or mismatching strategy. It was most effective to match cognitive treatments with cognitive attacks, but matching affective treatments with affective attacks was ineffective in conferring resistance.

In a later study, Pfau, Szabo, and colleagues (2001) hypothesized that, because cognitive pretreatment messages would provide refutational content, these messages would be superior in conferring resistance to counterattitudinal messages by bolstering cognitive counterarguing. Furthermore, the researchers hypothesized that affective-anger messages would lead to greater message scrutiny, and thus more resistance to influence, and would invoke more cognitive counterarguing than affective-happiness inoculation messages. While the researchers found that all three types of inoculation messages (cognitive, affective-anger, and affective-happiness) promote resistance to influence, they found little differentiation among the three approaches, with affective-happiness conferring the most resistance yet, surprisingly, motivating no more threat and generating no more counterarguing output. Additionally, this investigation employed attack messages that were a blend of cognitive and affective approaches, so a matched and mismatched comparison was not investigated.

The researchers designed the inoculation affective messages to induce feelings of affect, including happiness and anger. The affect manipulations, based solely on text, were weak. However, the studies make a valuable contribution to our understanding of the inoculation process of resistance, highlighting intrinsic message features. O'Keefe (2003) recently argued that persuasive message effects research should be less concerned with affect inductions and, instead, concerned with pinpointing the effects of intrinsic message features. O'Keefe (2003) argued, “[W] hen the research question concerns the effect of a message variation on a persuasive outcome, no message manipulation check is required" (p. 257), specifically citing fear- and guilt-appeal persuasion research as examples where learning more about intrinsic message functions is more important than affect responses to the messages. "An effect-based definition of fear appeal variations is, in the end, undesirable, precisely because it avoids analysis of intrinsic message features and so makes fear appeal research shed little light on communication processes" (O'Keefe, 2003, p. 265).

Whether a matched or mismatched strategy is more effective in influencing attitudes is unclear. Edwards' (1990) research suggests that a matching strategy is superior in terms of persuasiveness, while Millar and Millar (1990) found a mismatching approach to be more effective in changing attitudes. However, Millar and Millar (1990) attributed the mismatching strategy's effectiveness to be based on not recognizing an attitude challenge. Inoculation messages explicitly prepare individuals for such challenges, suggesting that the inoculation treatment may account for the mismatching strategy's effectiveness. 
More applicable to this current investigation, Lee and Pfau (1998) conducted the only study that compared matching and mismatching in inoculation. No clear delineations can be made in terms of whether a matching or mismatching strategy is more effective. Cognitive inoculation treatments conferred resistance to cognitive attacks, supporting a matching approach, yet affective treatments were not successful in the face of affective attacks, supporting a mismatched approach.

To examine further the effectiveness of matching versus mismatching in terms of inoculation strategies and subsequent attack messages, we offer the following hypotheses based on Lee and Pfau's (1998) findings regarding cognitive and affective treatment messages and attack messages:

H4: A matching strategy is more effective than a mismatching strategy with rational inoculation treatments, measured by (a) attitudinal resistance and (b) attack source derogation.

H5: A mismatching strategy is more effective than a matching strategy with affective inoculation treatments, measured by (a) attitudinal resistance and (b) source derogation.

H6: Rational inoculation treatment messages will enhance counterarguing and refutational output when compared with affective inoculation treatments in the face of (a) affective attack messages and (b) rational attack messages.

\section{Method}

\section{Participants}

Participants were recruited from communication courses at a midwestern university, with the incentive of course credit. All participants were at least 18 years of age and signed informed consent forms. Participants were told they were taking part in a study of information processing. A total of 225 students (135 female, 90 male) completed the study.

\section{Design and Measures}

The independent variable in this experiment was treatment condition (inoculated or control), with effects examined on nine dependent variables. Receivers' prior attitudinal position toward the topic functioned as a covariate. Consistent with prior inoculation research, initial attitudinal position toward the topic was assessed using bipolar adjective pairs (Burgoon, Cohen, Miller, \& Montgomery, 1978). The reliability coefficient for initial attitude toward plagiarism was .94.

Threat generated by the inoculation messages was assessed using five bipolar adjective pairs. In the context of inoculation research, threat is conceptualized as the realization that one might encounter a counterattitudinal message designed to sway an existing attitude (e.g., Pfau et al., 2004, 2006). The reliability of the threat measure was .94. 
We used the attitude scale developed by Burgoon et al. (1978) during Phases 2 and 3. Alpha reliabilities of the attitude scale were .94 at Phase 2 and .95 at Phase 3.

Issue involvement, operationalized as "the importance or salience of the topic" (Pfau, Tusing, Koerner, et al., 1997, p. 18), was measured using an abbreviated version of the Personal Involvement Inventory (PII; Zaichkowsky, 1985). The alpha reliability score for issue involvement was .95 at Phase 3.

The perceived credibility of the source of the attack message was assessed at Phase 3 using three bipolar adjective pairs for three dimensions of credibility (McCroskey, Holdridge, \& Toomb, 1974; McCroskey, Jensen, \& Valencia, 1973). The alpha reliabilities of these scales were $.89, .87$, and .86 , respectively.

Attitude accessibility was assessed at Phase 3 for all participants using Krosnick, Boninger, Chuang, Berent, and Carnot's (1993) thinking and talking protocol. Respondents were asked how often they thought about and talked about the issue of plagiarism. The wording of the items was as follows: "Compared to other issues, how often do you think about [or for the next item, how often do you discuss with friends, family members, or others] the issue of plagiarism?" The reliability of the attitude accessibility measures was .80 .

Vested interest has not been explored in previous inoculation research. Crano's (1995) conception of vested interest is grounded in an attitudinal object's hedonic importance, with highly vested attitudes more predictive of behavior. Vested interest is a conglomeration of five components: stake, salience, certainty, immediacy, and self-efficacy (Crano, 1995). These five factors were assessed using five bipolar phrases: significant stake in the issue/insignificant stake in the issue, think of the issue a lot/ seldom think of the issue, certain that this issue affects me/uncertain that this issue affects me, issue will affect me soon/issue will not affect me soon, and strong personal ability to handle this issue/weak personal ability to handle this issue. Alpha reliability was .74 for this created scale.

Counterarguing was assessed using a checklist technique first utilized by Pfau et al. (2004, 2006). This technique presents participants with a list of 20 arguments, including some that were included in the inoculation treatment and in attack messages and some that were not. Each participant was asked to check off those opposing arguments that they believed other people had that ran contrary to the participant's own attitude but that entered their mind during the completion of attitude measures. During the next part of this checklist procedure, the participants went back through the 20 arguments and checked those that entered their mind as reasons why the opposing arguments were wrong: refutations.

\section{Experimental Materials}

Inoculation treatment messages were written by the researchers as original essays using support drawn from popular press articles and from scholarly journals. The two affect-based inoculation treatment messages (fear and guilt) were written using affect-laden language. The fear-based message focused on the likelihood that students who plagiarize would be caught (e.g., "There is no safety and security for cheaters. 
They face detection. These students have much to fear!"). The guilt-based message used an anticipated guilt strategy, describing students' feelings of guilt after cheating (e.g., "Considering the impacts ... it's no surprise that students often experience intense guilt after turning in plagiarized ... assignments") and the hurt plagiarism causes professors (e.g., "It always makes me sick to my stomach when I discover a student has cheated").

The rational inoculation treatment message was written using evidence and rational arguments and avoided affect-laden language (e.g., "With one new user of the turnitin.com service every 20 seconds, the odds are not in the cheater's favor. Cheating just doesn't make sense").

To highlight the differences between message types, participants were given the following instructions before reading the inoculation treatment messages: before the rational treatment message, participants were asked to "analyze WHY you feel the way you do about the issue introduced in the following message. That is, go over in your mind what it is about the issue that makes you think you support it or not," whereas participants in the affective treatment conditions were asked to "analyze HOW you feel while reading the following message. That is, go over in your mind how you are feeling while you are reading about this issue" (Millar \& Tesser, 1986, p. 272).

The first paragraph of each inoculation message was designed to elicit threat. As in previous inoculation research, threat was operationalized as a warning of an impending and potentially influential attack against the individual's current attitude toward plagiarism. This warning of an impending attitude attack was followed by opposing arguments (arguments that justified plagiarism) and then refutations of these counterarguments.

Two types of attack messages were written for this study. As with the inoculation treatment messages, these messages were written by the researchers as original essays. The messages were not attributed to any specific source. One used affective appeals, relying on emotional anecdotes and affect-laden language. For example, the affective attack message included an anecdote about a student falsely accused of plagiarism, followed by the statement, "These are pure, shameful cases of maddening injustice, and it's no surprise that students are very angry." The other attack message made rational, evidence-based arguments. For example, one argument offered evidence that most students cheat, followed by this rationale: "It is not rational to destroy a student's academic or professional life for doing something that most people do." Participants were randomly assigned to one of the three treatment conditions and the two attack message conditions.

Inoculation and attack messages were evaluated for written comprehension using the Index of Contingency (Becker, Bavelas, \& Braden, 1961), a measure that interprets the readability of sentences. With this measurement, lower numbers suggest diversity in language while higher ratings indicate repetition in word choices. The ratings for the attack messages were 26.7 and 26.3. Index of Contingency ratings for all three inoculation pretreatment messages were 26.3, suggesting equivalence. 


\section{Procedure}

During Phase 1, participants completed questionnaires that gathered demographic information and assessed initial attitudes toward the issue of plagiarism. During Phase 2, occurring approximately two weeks after Phase 1, participants were presented with the inoculation treatment message and then completed scales designed to assess attitudes, involvement levels, and vested interest. Participants in the control condition only completed the scales. Finally, during Phase 3, occurring approximately two weeks after Phase 2, all participants encountered an attack message, which attempted to justify plagiarism using either affective or rational justifications. All participants then completed scales assessing attitudinal valence, attitude accessibility, involvement levels, and vested interest.

\section{Results}

\section{Manipulation Check}

Threat is a requisite for inoculation (McGuire, 1962; Pfau, 1997). Although a planned comparison revealed no overall threat finding, Scheffe's post-hoc tests indicated that inoculated participants experienced greater threat than controls with fear-based treatments, $t(120)=3.07, p<.01$; guilt-based treatments, $t(122)=2.00, p<.05$; and rational-based treatments, $t(113)=1.92, p<.05$, one-tailed.

\section{Statistical Analysis}

In the first phase of analysis, a one-way ANCOVA was computed, with experimental condition (control, fear-based, guilt-based, and cognitive-based) as the independent variable and initial attitude toward the issue of plagiarism as the covariate. ANCOVA omnibus effects were followed by assessment of means using Dunn's multiple comparison procedure for predicted effects (Kirk, 1995) and by Scheffe's post-hoc tests for unpredicted effects.

The ANCOVA indicated significance for the covariate of initial attitude, $F(11,212)=11.69, p<.01$, eta ${ }^{2}=.38$. The ANCOVA did not reveal a significant main effect for experimental condition. However, to investigate more specifically any effects on the processes of inoculation and to compare the means of the specific inoculation treatments, we computed Dunn's multiple comparisons and, when appropriate, Sheffe's post-hoc tests to assess patterns of means. Following nonsignificant omnibus tests with univariate tests is consistent with Huberty and Morris's (1989) justification for testing multiple means, even when the omnibus results are not significant, when theory posits the predicted effects.

\section{Assessment of Hypotheses}

Hypothesis 1 posited that inoculation treatment messages successfully confer attitudinal resistance to plagiarism justifications. Hypothesis 1 was not supported (Table 1). The planned comparisons indicated no significant differences in attitudes 
Table 1 Means for Treatment Conditions using Conventional Explanation of Inoculation

\begin{tabular}{|c|c|c|c|c|}
\hline \multirow[b]{2}{*}{ Dependent measure } & \multicolumn{4}{|c|}{ Experimental condition } \\
\hline & Control & Fear & Guilt & Rational \\
\hline Phase 2 Elicited threat & $\begin{array}{l}3.19(1.65) \\
n=58\end{array}$ & $\begin{array}{l}3.62_{\mathrm{a}}(1.46) \\
n=64\end{array}$ & $\begin{array}{l}3.47_{\mathrm{b}}(1.53) \\
n=66\end{array}$ & $\begin{array}{l}3.46_{\mathrm{c}}(1.64) \\
n=57\end{array}$ \\
\hline Phase 2 Attitude toward plagiarism & $\begin{array}{l}2.20(1.13) \\
n=59\end{array}$ & $\begin{array}{l}2.13(1.05) \\
n=64\end{array}$ & $\begin{array}{l}1.94_{\mathrm{a}}(1.03) \\
n=66\end{array}$ & $\begin{array}{l}2.15(1.10) \\
n=57\end{array}$ \\
\hline $\begin{array}{l}\text { Phase } 3 \text { Attitude toward position } \\
\text { in attack message }\end{array}$ & $\begin{array}{l}3.02(1.33) \\
n=53\end{array}$ & $\begin{array}{l}3.21(1.41) \\
n=61\end{array}$ & $\begin{array}{l}3.08(1.36) \\
n=66\end{array}$ & $\begin{array}{l}3.12(1.47) \\
n=56\end{array}$ \\
\hline Phase 3 Involvement & $\begin{array}{l}4.39(1.63) \\
n=52\end{array}$ & $\begin{array}{l}4.87_{\mathrm{a}}(1.19) \\
n=61\end{array}$ & $\begin{array}{l}4.72_{\mathrm{a}}(1.41) \\
n=65\end{array}$ & $\begin{array}{l}4.63_{\mathrm{d}}(1.41) \\
n=57\end{array}$ \\
\hline Phase 3 Accessibility & $\begin{array}{l}2.12(1.03) \\
n=53\end{array}$ & $\begin{array}{l}2.40_{\mathrm{c}}(1.25) \\
n=61\end{array}$ & $\begin{array}{l}2.23(1.22) \\
n=66\end{array}$ & $\begin{array}{l}2.38_{\mathrm{c}}(1.21) \\
n=57\end{array}$ \\
\hline Phase 3 Vested interest & $\begin{array}{l}3.50(1.24) \\
n=53\end{array}$ & $\begin{array}{l}3.70_{\mathrm{c}}(1.25) \\
n=61\end{array}$ & $\begin{array}{l}3.53(1.13) \\
n=66\end{array}$ & $\begin{array}{l}3.74_{\mathrm{b}}(1.40) \\
n=56\end{array}$ \\
\hline Phase 3 Character & $\begin{array}{l}3.57(1.15) \\
n=53\end{array}$ & $\begin{array}{l}3.49(1.34) \\
n=61\end{array}$ & $\begin{array}{l}3.60(1.45) \\
n=66\end{array}$ & $\begin{array}{l}3.51(1.23) \\
n=56\end{array}$ \\
\hline Phase 3 Competence & $\begin{array}{l}3.94(1.27) \\
n=53\end{array}$ & $\begin{array}{l}3.64_{\mathrm{b}}(1.40) \\
n=61\end{array}$ & $\begin{array}{l}3.88(1.51) \\
n=66\end{array}$ & $\begin{array}{l}3.82(1.37) \\
n=56\end{array}$ \\
\hline Phase 3 Sociability & $\begin{array}{l}4.08(1.03) \\
n=53\end{array}$ & $\begin{array}{l}4.03(1.07) \\
n=61\end{array}$ & $\begin{array}{l}4.01(1.29) \\
n=66\end{array}$ & $\begin{array}{l}4.26_{\mathrm{d}}(1.25) \\
n=56\end{array}$ \\
\hline
\end{tabular}

Note. Means and standard deviations are displayed (latter in parentheses). Elicited threat was measured using a seven-point scale. Higher scores indicate greater elicited threat. Phase 2 attitude toward plagiarism and Phase 3 variables were assessed using seven-point scales. Higher scores of attitude toward position in attack message, character, competence, and sociability indicate less resistance to the attack message.

a Significant compared to control condition at $p<.01$.

${ }^{\mathrm{b}}$ Significant compared to control condition at $p<.05$.

'Significant compared to control condition at $p<.05$, one-tailed.

${ }^{\mathrm{d}}$ Approaching significance compared to control condition at $p<.10$, one-tailed.

toward the position in the attack message between the treatment and control conditions. Post-hoc tests indicated that the guilt-based inoculation treatment message did immediately result in a more negative attitude valence toward plagiarism at Phase $2, t(117)=3.25, p<.01$, but there were no statistical differences in attitude valence toward the attack message at Phase 3.

Hypothesis 2 examined whether inoculation treatments: (a) enhance base involvement levels; (b) elicit attitude accessibility; and (c) increase perception of vested interest, when compared to controls. Hypothesis 2a was supported (Table 1). Although a planned comparison revealed no overall issue involvement finding, Scheffe's post-hoc tests indicated that inoculated participants had increased issue involvement, including those receiving inoculation treatments based on fear, $t(111)=3.69, \quad p<.01 ;$ guilt, $t(115)=2.75, \quad p<.01$; and rational arguments, $t(107)=1.85, p<.05$, one-tailed. Inoculation pretreatment messages, regardless of type, enhanced issue involvement. 
Hypothesis $2 \mathrm{~b}$ was partially supported (Table 1). Post-hoc tests indicated that fearbased inoculation treatment messages, $t(112)=2.54, p<.01$, one-tailed, and rational inoculation treatment messages, $t(108)=2.36, p<.01$, one-tailed, significantly enhanced the attitude accessibility of inoculated participants compared to those not receiving an inoculation treatment message (controls). Guilt-based inoculation treatments failed to enhance accessibility, accounting for the null result of the planned comparison.

Hypothesis $2 \mathrm{c}$ stated that inoculation treatment messages would increase the perception of vested interest in the issue of plagiarism. Hypothesis $2 \mathrm{c}$ was partially supported (Table 1). Post-hoc tests indicated that fear-based inoculation, $t(112)=$ $1.82, p<.05$, one-tailed, and rational inoculation, $t(107)=2.00, p<.05$, significantly enhanced students' perceptions of vested interest in plagiarism. The guilt-based condition did not affect students' perceptions of their vested interest in the issue.

Hypothesis 3 stated that students who received inoculation treatment messages would derogate the source of a pro-plagiarism message more than those in the control group, perceiving the source of the attack message to be (a) less competent, (b) of poorer character, and (c) of lower sociability. Hypothesis 3a was not supported (Table 1). Planned comparisons did not indicate significant differences between those inoculated and those in the control condition.

Hypothesis 3 b was partially supported (Table 1). Post-hoc tests indicated that only the fear-based inoculation treatment significantly decreased students' perceptions of the competence of the source of the attack message, $t(112)=2.31, p<.05$.

Hypothesis $3 c$ was not supported (Table 1). Planned comparisons did not indicate any differences between those inoculated and those in the control condition. While there were some differences between controls and those in the fear-based and guiltbased treatment conditions in terms of the perceived sociability of the attack message's source, in the direction hypothesized, post-hoc tests indicated that the differences were not significant. With the exception of the fear-based inoculation treatment condition, inoculation failed to derogate the source of the subsequent attack message. None of the three treatment conditions had effects on the source's character, and none decreased perceptions of the source's sociability.

Hypothesis 4 proposed that a matching strategy would be more effective than a mismatching strategy with rational inoculation treatments, measured by (a) attitudinal resistance and (b) attack source derogation. Hypothesis 4a received partial support (Table 2). Dunn's planned comparison of the two affective treatment conditions compared to the rational treatment condition in the face of a rational attack revealed no significant results in terms of attitudinal resistance. A post-hoc test, however, found that the rational treatment was more effective than the fear treatment, $t(57)=1.68, p<.05$, one-tailed.

Results indicated partial support for Hypothesis $4 \mathrm{~b}$ (Table 2). When comparing the guilt-based and fear-based affective treatments with the rational treatment, significant differences emerged for the guilt-based treatment. The rational treatment was significantly more effective than the guilt-based treatment in derogating the source's character, $t(67)=3.06, p<.01$, and rational treatment was significantly more effective 
Table 2 Means for Treatment Conditions Encountering Rationality-Based Attacks in Phase 3

\begin{tabular}{llll}
\hline & \multicolumn{3}{c}{ Experimental condition } \\
\cline { 2 - 4 } Dependent measure & \multicolumn{1}{c}{ Fear } & \multicolumn{1}{c}{ Guilt } & \multicolumn{1}{c}{ Rational } \\
\hline P3 Attitude toward position in attack message & $3.29(1.39)$ & $3.18(1.37)$ & $2.97_{\mathrm{c}}(1.50)$ \\
& $n=28$ & $n=39$ & $n=31$ \\
P3 Perceived character & $3.56(1.40)$ & $3.88(1.35)$ & $3.39_{\mathrm{b}}(1.32)$ \\
& $n=28$ & $n=39$ & $n=30$ \\
P3 Perceived competence & $3.83(1.36)$ & $4.30(1.34)$ & $3.73_{\mathrm{b}}(1.35)$ \\
& $n=28$ & $n=39$ & $n=30$ \\
P3 Perceived sociability & $4.21(1.05)$ & $4.24(1.25)$ & $4.25(1.15)$ \\
& $n=28$ & $n=39$ & $n=30$ \\
Counterarguing output & $7.48(2.98)$ & $8.97(2.83)$ & $9.10_{\mathrm{a}}(3.14)$ \\
& $n=27$ & $n=39$ & $n=30$ \\
Refutational output & $7.81(3.74)$ & $8.87(3.63)$ & $9.17_{\mathrm{a}}(3.07)$ \\
& $n=27$ & $n=39$ & $n=30$ \\
\hline
\end{tabular}

Note. Means and standard deviations are displayed (latter in parentheses). Attitude toward position in attack message, perceived character, perceived competence, and perceived sociability were assessed using seven-point scales, with higher scores indicating less resistance to the attack message. Counterarguing and refutational outputs were measured using the checklist procedure, as described in the Design and Measures section.

${ }^{a}$ Significant compared to fear condition at $p<.01$.

${ }^{\mathrm{b}}$ Significant compared to guilt condition at $p<.01$.

'Significant compared to fear condition at $p<.05$, one-tailed.

than guilt-based treatment in derogating the source's competence, $t(67)=3.56$, $p<.01$.

Hypothesis 5 predicted that a mismatching strategy would be more effective than a matching strategy with affective inoculation treatments, measured by (a) attitudinal resistance and (b) source derogation.

Hypothesis 5a was not supported (Table 3). Dunn's planned comparison of the two affective treatment conditions to the rational treatment condition in the face of an affective attack revealed no significant results in terms of attitudinal resistance. Contrary to prediction, a post-hoc test indicated that the guilt-based inoculation strategy was more effective in conferring attitudinal resistance than the rational treatment message, $t(50)=2.00, p<.05$. There were no significant differences between the fear-based treatment and the rational treatment.

To test Hypothesis 5b, we first conducted Dunn's planned comparisons between the two affect-based treatments and the rational treatment on the three dimensions of source credibility: character, competence, and sociability. There was no difference in perceived competence or character of the attack message when comparing the matching and mismatching strategies in the face of an affective attack. Additionally, contrary to prediction, the matching strategy was more effective than a mismatching strategy in terms of sociability; participants who received the affective inoculation 
Table 3 Means for Treatment Conditions Encountering Affect-Based Attacks in Phase 3

\begin{tabular}{llll}
\hline & \multicolumn{3}{c}{ Experimental condition } \\
\cline { 2 - 4 } Dependent measure & \multicolumn{1}{c}{ Fear } & \multicolumn{1}{c}{ Guilt } & \multicolumn{1}{c}{ Rational } \\
\hline P3 Attitude toward position in attack message & $3.15(1.44)$ & $2.92_{\mathrm{b}}(1.36)$ & $3.30(1.45)$ \\
& $n=33$ & $n=27$ & $n=25$ \\
P3 Perceived character & $3.43_{\mathrm{e}}(1.30)$ & $3.20_{\mathrm{a}}(1.50)$ & $3.64(1.12)$ \\
& $n=33$ & $n=27$ & $n=26$ \\
P3 Perceived competence & $3.47_{\mathrm{b}}(1.44)$ & $3.27_{\mathrm{a}}(1.56)$ & $3.92(1.41)$ \\
& $n=33$ & $n=27$ & $n=26$ \\
P3 Perceived sociability & $3.87_{\mathrm{a}}(1.09)$ & $3.68_{\mathrm{a}}(1.31)$ & $4.27(1.37)$ \\
& $n=33$ & $n=27$ & $n=26$ \\
Counterarguing output & $8.06(3.40)$ & $9.31_{\mathrm{a}}(3.91)$ & $7.61(2.93)$ \\
& $n=33$ & $n=26$ & $n=26$ \\
Refutational output & $7.91(3.53)$ & $9.19_{\mathrm{a}}(4.71)$ & $7.77(2.57)$ \\
& $n=33$ & $n=26$ & $n=26$ \\
\hline
\end{tabular}

Note. Means and standard deviations are displayed (latter in parentheses). Attitude toward position in attack message, perceived character, perceived competence, and perceived sociability were assessed using seven-point scales, with higher scores indicating less resistance to the attack message. Counterarguing and refutational outputs were measured using the checklist procedure, as described in the Design and Measures section.

${ }^{a}$ Significant compared to rational condition at $p<.01$.

${ }^{\mathrm{b}}$ Significant compared to rational condition at $p<.05$.

${ }^{\mathrm{c}}$ Significant compared to rational condition at $p<.01$, one-tailed.

${ }^{\mathrm{d}}$ Significant compared to rational condition at $p<.05$, one-tailed.

${ }^{\mathrm{e}}$ Significant compared to rational condition at $p<.10$, one-tailed.

treatments perceived the source of the attack message as less sociable, $F(1,105)=3.27$, $p<.01, e t a^{2}=.05$.

We then compared the individual affective strategies of fear and guilt with the rational treatment on the three dimensions of source credibility (Table 3). In terms of perceived character of the affective attack message's source, contrary to prediction the guilt-based inoculation treatment message was more effective in derogating the source than the rational treatment message, $t(51)=2.75, p<.01$. Additionally, the fear-based inoculation treatment message approached significance in derogating the source when compared to the rational treatment message, $t(57)=1.31, p<.10$, one tailed. Also contrary to prediction, in terms of perceived competence of the affective attack message's source, the guilt-based treatment, $t(51)=3.25, p<.01$, and the fear-based treatment, $t(57)=2.36, p<.05$, were more effective in derogating the source than the rational treatment message. In terms of perceived sociability of the attack message's source, the guilt-based treatment, $t(51)=3.69, p<.01$, and fear-based treatment, $t(57)=2.67, p<.01$, were more effective in derogating the source than the rational treatment message. Results indicate that a matching strategy is more effective than a mismatching strategy with affective inoculation treatments.

Hypothesis 6 posited that rational treatments would elicit more counterarguing output when compared to affective treatments in the face of (a) affective attacks, and 


\section{J. Compton \& M. Pfau}

(b) rational attacks. Hypothesis 6a was not supported (Table 3). First, Dunn's planned comparison indicated no significant difference between the combined affective and rational treatments. Post-hoc tests indicated not only that the rational treatment fail to elicit more opposing arguments and refutational output in the face of affective attacks, but also that the guilt-based treatment was more effective than the rational treatment. The guilt-based treatment enhanced counterarguing, $t(50)=3.69$, $p<.01$, and refutational output, $t(50)=2.90, p<.01$, more than the rational treatment, in the face of affective attacks.

Hypothesis $6 \mathrm{~b}$ was partially supported (Table 2). Although planned comparisons indicated no significant difference between the combined affective and rational treatments, post-hoc tests showed differences between specific strategies. The rational treatment elicited more counterarguing output than the fear-based treatment, $t(55)=4.05, p<.01$, and elicited more refutational output than the fear-based treatment, $t(55)=2.89, p<.01$. These results indicate that the matching strategy is more effective than the mismatching strategy in terms of counterarguing output.

\section{Discussion}

Plagiarism continues to be a serious problem on university campuses. This investigation assessed the effectiveness of inoculation treatment messages in enabling students to resist justifications for plagiarizing. While the results suggest some encouraging effects of inoculation treatment messages with the topic of plagiarism, the failure of any of the treatment conditions to confer attitudinal resistance to the justification attack message was disappointing. There was some effectiveness in derogating the source of the attack message, with the fear-based message decreasing perceptions of the competence of the attack message's source. Contrary to prediction, the rationality-based inoculation message actually enhanced perceptions of the sociability of the pro-plagiarism message's source. The results of this study indicate that using fear-based inoculation messages may be partly successful in combating plagiarism, but that there are risks in employing a rationality-based inoculation strategy.

The most important theoretical findings from this study are those that shed more light on the process of inoculation. First, this study confirms previous findings that inoculation treatment messages increase base involvement levels (Compton \& Pfau, 2004; Pfau et al., 2004) and enhance attitude accessibility (Compton \& Pfau, 2004; Pfau et al., 2003Pfau et al., 2004).

This study was the first to assess whether inoculation affected vested interest, and we found that inoculation can enhance vested interest in the issue. This finding is important, as vested interest plays a critical role in whether attitudes influence behaviors (Crano, 1995). Students in all conditions reported negative attitudes toward plagiarism; consequently, enhancing vested interest should further discourage plagiarism.

This study also examined whether matching affective and rational bases of inoculation treatments with subsequent attack messages was more effective than 
mismatching in conferring attitudinal resistance and derogating the source of the attack message. Early attitude research had conflicting findings regarding whether a matching or mismatching strategy is more persuasive, with some studies indicating the superiority of a matching approach (e.g., Edwards, 1990) and others finding support for a mismatching approach (e.g., Millar \& Millar, 1990). However, the focus of this study was not on which message strategy was more persuasive but, instead, which strategy was more effective in conferring resistance. For guidance in this focus, we used the previous findings of Lee and Pfau (1998) and predicted that matching would work best when the attack is rationality-based (i.e., rationalitybased inoculation treatments are more effective than affective-based inoculation treatments when the attack message is rationality-based), and that mismatching would work better when the attack is affective (i.e., affect-based inoculation treatments are more effective than rationality-based treatments when the attack message is affect-based.).

As predicted, a matching strategy was more effective than a mismatching strategy with rationality-based treatments. Students who read a rationality-based inoculation treatment message, and then encountered a message justifying plagiarism and using rationality-based arguments, had more negative attitudes toward the message, derogated the source of the message in terms of character and competence, and had enhanced counterarguing and refutational output at the time of encountering the attack message when compared to students who received either a fear-based or a guilt-based inoculation treatment. The superiority of a matching strategy with rationality-based attacks is consistent with previous findings (Lee \& Pfau, 1998) and suggests that students who try to rationalize their decision to plagiarize need to have an arsenal of cognitive argumentation to resist.

Contrary to prediction, a matching strategy was also more effective with affective treatments. Students who received a guilt-based inoculation treatment, and then encountered a message justifying plagiarism and using affect-based arguments, had more negative attitudes toward the message justifying plagiarism, derogated the source of the message in terms of character, competence, and sociability, and had enhanced counterarguing and refutational output at the time of encountering the attack message when compared to students who received a rationality-based inoculation treatment. We found some of these effects with the fear-based inoculation treatment too. Students receiving a fear-based inoculation treatment derogated the source in terms of character, competence, and sociability. However, the fear-based treatments were no more effective than the rationality-based treatments in the face of an affect-based attack in terms of attitude toward the message or counterarguing and refutational output.

The finding that matching is more effective than mismatching, even in the face of affect-based treatments, conflicts with Lee and Pfau's (1998) finding that affect-based treatments were ineffective in the face of affect-based attacks. One explanation for the different findings is that Lee and Pfau did not assess specific affect strategies, like fear and guilt, but instead looked at general affect in terms of emotions and feelings generated by the inoculation treatment. Our findings suggest that, when specifically 
using fear-based arguments in the inoculation treatment message, a matching strategy is superior with affect-based attacks.

Combating plagiarism is no easy task. The results of this study indicate that, while affect- and rationality-based inoculation treatments elicit threat, only the guilt-based treatment has an immediate effect on attitudes toward plagiarism, and none of the treatments confer ultimate resistance at the time of encountering a counterattitudinal message (i.e., a message that justifies plagiarism). Nevertheless, there is reason for optimism when considering an inoculation strategy to fight plagiarism. All inoculation treatments enhanced base involvement levels, two inoculation strategies enhanced vested interest and attitude accessibility, and the fear-based strategy derogated the source of the message in terms of perceived competence.

There are limitations to the design of this study. While the written messages employed in our experimental design afford useful control and consistency, there are differences between written pro-plagiarism messages and the temptation to plagiarize. Also, our current study fails to account for cultural differences. As recent scholarship has noted, culture affects how plagiarism is defined and evaluated (e.g., Roig \& Caso, 2005). Ashworth, Freewood, and Macdonald (2003) argued that plagiarism "is a notion specific to a particular culture and epoch, and is also understood in a variety of ways by individuals" (p. 257). Future studies should account for how culture influences the efficacy of inoculation treatments in the context of plagiarism. Finally, although students were assured that their responses would be anonymous, there is a possibility that self-reports of attitudes toward plagiarism were not entirely indicative.

\section{Practical Applications}

"In an ideal world," David Glenn wrote in a special report on plagiarism appearing in The Chronicle of Higher Education in 2004, "academe would respond to plagiarism allegations with a sure and swift machinery of justice" (p. A16). We proposed in this study that it would be even more valuable to stop plagiarism before it happens with inoculation strategies. Our hope was that inoculation would bolster students' healthy attitudes to plagiarism, to protect them against pro-plagiarism justifications. While the results were not as strong as we had hoped, the findings offer practical guidance for the way universities fight student plagiarism offenses.

The idea that plagiarism prevention strategies should be employed early in a student's academic path is not new. This is consistent with other plagiarism and academic dishonesty studies (e.g., Bennett, 2005). Perhaps more importantly, our results offer support for two-sided plagiarism messages, whereby students are not only informed why they should not plagiarize but also guided through refutations of arguments for why they should. This inoculation strategy resulted in immediate attitude changes, including changes in accessibility and vested interest, resulting in stronger, healthy attitudes about plagiarism. Additionally, we argue that a focus on preemptive strategies is needed. While reactive strategies (e.g., punishments) and detection methods (e.g., software) are useful tools in fighting plagiarism (see 
Underwood \& Szabo, 2003; Woessner, 2004), stopping plagiarism before it occurs would be ideal.

We suggest that an inoculation strategy to discourage plagiarism should not replace current methods of teaching academic honesty practices. Instead, the inoculation strategy can be used as a guide for discussions with students about plagiarism, or can be used in conjunction with practice in identifying plagiarism or improper source citations. A discussion guided by an inoculation strategy could involve students reading inoculation messages (messages about plagiarism that raise and refute arguments about plagiarism). Discussions could be more student-generated by asking students to come up with reasons they think students might give to justify plagiarism and then guiding students in refutations of these arguments. These discussions could also be accompanied by plagiarism definitions, tips, and practice, such as in the plagiarism prevention activity described by Schuetze (2004).

As the matching/mismatching findings indicate, understanding the bases for students' attitudes toward plagiarism is critical. When students encounter rational reasons to plagiarize, they need rational reasons not to plagiarize; when students experience affect-based reasons to plagiarize, they need affect-based reasons to resist. Inoculation-based messages are the ideal springboard for such discussions, as they can raise and refute both rational and affect-based arguments. Dialogue with students, using an inoculation approach of raising and refuting counterarguments, can help identify these diverse attitudes toward plagiarism.

Discussions of guilt, including anticipatory guilt, seem potentially fruitful in light of our study results. Of the three message types, guilt was the most effective, with immediate impacts on students' attitudes toward plagiarism. At the conclusion of their investigation of fraudulent excuses, Roig and Caso (2005) asserted: "As with other traditional forms of cheating, students' successful use of fraudulent excuses gives them an undeserved advantage and is unfair to their peers who are honest" (p. 493). Our study suggested that communicating this idea to students before they are tempted to plagiarize helps bolster their healthy attitudes against plagiarism. While there are many ways to integrate affect into plagiarism messages to students, one of the most practical forums would be course syllabi. A statement such as "Imagine how your classmates would feel if they discovered the unfair advantage you gained by plagiarizing your work," may serve as a springboard for classroom discussion and help to promote healthy attitudes against plagiarism.

There is reason for both optimism and concern when interpreting the effects of the fear-based inoculation message. Students who read a fear-based inoculation message were more likely to derogate the source of the pro-plagiarism essay. While this could lead to rejection of pro-plagiarism arguments, resistance based on source derogation may not be long-lasting. Additionally, source derogation is not conducive to promoting a dialogue with students about their attitudes toward plagiarism. The results from this study suggest that fear-based inoculation messages have a resistance effect but that there may be a cost involved in employing them.

The results of the rational inoculation treatment message should give us pause. The rational inoculation message was ineffective in conferring resistance to 
pro-plagiarism messages but, more notably, enhanced perceptions of the source of the pro-plagiarism justification essay. What are we to make of the way rational evidence and arguments affect students' perceptions of plagiarism? Using rational-choice theory, Woessner (2004) concluded that, with "slap on the wrist" penalties for students, it is actually a rational decision for students to plagiarize. "By relying on policies that emphasize leniency, faculty members actually promote rather than discourage plagiarism" (p. 313). Using Woessner's (2004) analysis as a springboard, we might conclude that the failure of the rationality-based inoculation message was not due to the message itself but, instead, to the discrepancy between the message and the reality it described. Consequently, it would be unwise to conclude from this study that rationality-based inoculation messages are ineffective. If, for example, penalties for plagiarism were consistently severe, as scholars such as Woessner (2004) recommend, perhaps rationality-based messages would be more effective. It will take more than innovative message strategies to fight plagiarism; there must be appropriate actions and policies behind the rhetoric.

\section{References}

An, C., \& Pfau, M. (2004). The efficacy of inoculation in televised political debates. Journal of Communication, 54, 421-436.

Ashworth, P., Freewood, M., \& Macdonald, R. (2003). The student lifeworld and the meanings of plagiarism. Journal of Phenomenological Psychology, 34, 257-278.

Becker, S. W., Bavelas, A., \& Braden, M. (1961). An index to measure contingency of English sentences. Language and Speech, 4, 138-145.

Bennett, R. (2005). Factors associated with student plagiarism in a post-1992 university. Assessment and Evaluation in Higher Education, 30, 137-162.

Burgoon, M., Cohen, M., Miller, M. D., \& Montgomery, C. L. (1978). An empirical test of a model of resistance to persuasion. Human Communication Research, 5, 27-39.

Burgoon, M., Pfau, M., \& Birk, T. (1995). An inoculation theory explanation for the effects of corporate issue/advocacy advertising. Communication Research, 22, 485-505.

Cohen, H. (2003, October 10). Internet plagiarism prevalent on campuses, study finds. University Wire. Retrieved October 16, 2003, from LexisNexis database.

Compton, J. A., \& Pfau, M. (2004). Use of inoculation to foster resistance to credit card marketing targeting college students. Journal of Applied Communication Research, 32, 343-364.

Compton, J. A., \& Pfau, M. (2005). Inoculation theory of resistance to influence at maturity: Recent progress in theory development and application and suggestions for future research. In P. J. Kalbfleisch (Ed.), Communication yearbook (Vol. 29, pp. 97-145). Mahwah, NJ: Lawrence Erlbaum Associates.

Crano, W. D. (1995). Attitude strength and vested interest. In R. E. Petty \& J. A. Krosnick (Eds.), Attitude strength: Antecedents and consequences (pp. 131-158). Mahwah, NJ: Erlbaum.

Dubé, L., Chattopadhyay, A., \& Letarte, A. (1996). Should advertising appeals match the basis of consumers' attitudes? Journal of Advertising Research, 36(6), 82-89.

Edwards, K. (1990). The interplay of affect and cognition in attitude formation and change. Journal of Personality and Social Psychology, 59, 202-216.

Fabrigar, L. R., \& Petty, R. E. (1999). The role of the affective and cognitive bases of attitudes in susceptibility to affectively and cognitively based persuasion. Personality and Social Psychology Bulletin, 25, 363-381.

Glenn, D. (2004). Judge or judge not? The Chronicle of Higher Education, 51(17), A16. 
Godbold, L. C., \& Pfau, M. (2000). Conferring resistance to peer pressure among adolescents: Using inoculation theory to discourage alcohol use. Communication Research, 27, 411-437.

Hawley, C. S. (1984). The thieves of academe. Improving College and University Teaching, 32, 35-39.

Huberty, C. J., \& Morris, J. D. (1989). Multivariate analysis versus multiple univariate analyses. Psychological Bulletin, 105, 302-308.

Johnson, B. T., \& Eagly, A. H. (1989). The effects of involvement on persuasion: A meta-analysis. Psychological Bulletin, 106, 290-314.

Kellogg, A. P. (2002). Students plagiarize online less than many think, a new study finds. The Chronicle of Higher Education, 48(23), 44-47.

Kirk, R. E. (1995). Experimental design: Procedures for the behavioral sciences (3rd ed). Pacific Grove, CA: Brooks/Cole Publishing Company.

Krosnick, J. A., Boninger, D. S., Chuang, Y. C., Berent, M. K., \& Carnot, C. G. (1993). Attitude strength: One construct or many related constructs? Journal of Personality and Social Psychology, 65, 1132-1149.

Landau, J. D., Druen, P. B., \& Arcuri, J. A. (2002). Methods for helping students avoid plagiarism. Teaching of Psychology, 29, 112-115.

Lee, W., \& Pfau, M. (1998, July). The effectiveness of cognitive and affective inoculation appeals in conferring resistance against cognitive and affective attacks. Paper presented at the annual conference of the International Communication Association, Jerusalem, Israel.

Love, P. G., \& Simmons, J. (1998). Factors influencing cheating and plagiarism among graduate students in the college of education. College Student Journal, 32, 539-550.

McCroskey, J. C., Holdridge, W., \& Toomb, J. K. (1974). An instrument for measuring the source credibility of basic communication instructors. Speech Teacher, 23, 26-33.

McCroskey, J. C., Jensen, T., \& Valencia, C. (1973, May). The measurement of the credibility of peers and spouses. Paper presented at the annual meeting of the International Communication Association, Montreal, Canada.

McGuire, W. J. (1962). Persistence of the resistance to persuasion induced by various types of prior belief defenses. Journal of Abnormal and Social Psychology, 64, 241-248.

McGuire, W. J. (1964). Inducing resistance to persuasion: Some contemporary approaches. In L. Berkowitz (Ed.), Advances in experimental social psychology (Vol. 1, pp. 191-229). New York: Academic Press.

Millar, M. G. (1992). Effects of experience on matched and mismatched arguments and attitudes. Social Behavior and Personality, 20, 47-56.

Millar, M. G., \& Millar, K. U. (1990). Attitude change as a function of attitude type and argument type. Journal of Personality and Social Psychology, 59, 217-228.

Millar, M. G., \& Tesser, A. (1986). Effects of affective and cognitive focus on the attitude-behavior relation. Journal of Personality and Social Psychology, 51, 270-276.

Moeck, P. G. (2002). Academic dishonesty: Cheating among community college students. Community College Journal of Research and Practice, 26, 479-491.

Moulton, J., \& Robinson, G. (2002). Plagiarism. In L. C. Becker \& C. B. Becker (Eds.), Encyclopedia of ethics (Vol. 3, 2nd ed., pp. 1316-1318). New York: Routledge.

O'Keefe, D. J. (2003). Message properties, mediating states, and manipulation checks: Claims, evidence, and data analysis in experimental persuasive message effects research. Communication Theory, 13, 251-274.

Park, C. (2003). In other (people's) words: Plagiarism by university students-literature and lessons. Assessment and Evaluation in Higher Education, 28, 471-488.

Petty, R. E., \& Cacioppo, J. T. (1979). Issue involvement can increase or decrease persuasion by enhancing message-relevant cognitive responses. Journal of Personality and Social Psychology, 37, 1915-1926.

Pfau, M. (1992). The potential of inoculation in promoting resistance to the effectiveness of comparative advertising messages. Communication Quarterly, 40, 26-44. 
Pfau, M. (1997). Inoculation model of resistance to influence. In G. A. Barnett \& F. J. Boster (Eds.), Progress in communication sciences: Advances in persuasion (Vol. 13, pp. 133-171). Greenwich, CT: Ablex.

Pfau, M., \& Burgoon, M. (1988). Inoculation in political campaign communication. Human Communication Research, 15, 91-111.

Pfau, M., Compton, J., Parker, K. A., An, C., Wittenberg, E. M., Ferguson, M., et al. (2006). The conundrum of the timing of counterarguing effects in resistance: Strategies to boost the persistence of counterarguing output. Communication Quarterly, 54, 143-156.

Pfau, M., Compton, J., Parker, K. A., Wittenberg, E. M., An, C., Ferguson, M., et al. (2004). The traditional explanation for resistance versus attitude accessibility: Do they trigger distinct or overlapping processes of resistance? Human Communication Research, 30, 329-360.

Pfau, M., Holbert, R. L., Zubric, S. J., Pasha, N. H., \& Lin, W. K. (2000). Role and influence of communication modality in the process of resistance to influence. Media Psychology, 2, 1-33.

Pfau, M., Kenski, H. C., Nitz, M., \& Sorenson, J. (1990). Efficacy of inoculation strategies in promoting resistance to political attack messages. Communication Monographs, 57, 25-43.

Pfau, M., Roskos-Ewoldsen, D., Wood, M., Yin, S., Cho, J., Kerr-Hsin, L., \& Shen, L. (2003). Attitude accessibility as an alternative explanation for how inoculation confers resistance. Communication Monographs, 70, 39-51.

Pfau, M., Szabo, E. A., Anderson, J., Morrill, J., Zubric, J., \& Wan, H. H. (2001). The role and impact of affect in the process of resistance to persuasion. Human Communication Research, 27, 216-252.

Pfau, M., Tusing, K. J., Koerner, A. F., Lee, W., Godbold, L. C., Penaloza, L. J., et al. (1997). Enriching the inoculation construct: The role of critical components in the process of resistance. Human Communication Research, 24, 187-215.

Pfau, M., \& Van Bockern, S. (1994). The persistence of inoculation in conferring resistance to smoking initiation among adolescents: The second year. Human Communication Research, 20, 413-430.

Pfau, M., Van Bockern, S., \& Kang, J. G. (1992). Use of inoculation to promote resistance to smoking initiation among adolescents. Communication Monographs, 59, 213-230.

Roig, M., \& Caso, M. (2005). Lying and cheating: Fraudulent excuse making, cheating, and plagiarism. The Journal of Psychology, 139, 485-494.

Schuetze, P. (2004). Evaluation of a brief homework assignment designed to reduce citation problems. Teaching of Psychology, 31, 257-259.

Stone, V. A. (1969). Individual differences and inoculation against persuasion. Journalism Quarterly, $46,267-273$.

Sutherland-Smith, W. (2005). The tangled web: Internet plagiarism and international students' academic writing. Journal of Asian Pacific Communication, 15(1), 15-29.

Szabo, E. A., \& Pfau, M. (2002). Nuances in inoculation: Theory and applications. In J. P. Dillard \& M. Pfau (Eds.), The persuasion handbook: Theory and practice (pp. 233-258). Thousand Oaks, CA: Sage.

Tannenbaum, P. H. (1967). The congruity principle revisited: Studies in the reduction, induction, and generalization of persuasion. In L. Berkowitz (Ed.), Advances in experimental social psychology (Vol. 3, pp. 271-320). San Diego, CA: Academic Press.

Tannenbaum, P. H., Macaulay, J. R., \& Norris, E. L. (1966). Principle of congruity and reduction of persuasion. Journal of Personality and Social Psychology, 3, 233-238.

Tannenbaum, P. H., \& Norris, E. L. (1965). Effects of combining congruity principle strategies for the reduction of persuasion. Sociometry, 28, 145-157.

Underwood, J., \& Szabo, A. (2003). Academic offences and e-learning: Individual propensities in cheating. British Journal of Educational Technology, 34, 467-477.

Wan, H.-H., \& Pfau, M. (2004). The relative effectiveness of inoculation, bolstering, and combined approaches in crisis communication. Journal of Public Relations Research, 16, 301-328. 
Whitley, B. E., Jr., \& Keith-Spiegel, P. (2002). Academic dishonesty: An educator's guide. Mahwah, NJ: Erlbaum.

Woessner, M. C. (2004). Beating the house: How inadequate penalties for cheating make plagiarism an excellent gamble. PS: Political Science and Politics, 37, 313-320.

Zaichkowsky, J. L. (1985). Measuring the involvement construct. Journal of Consumer Research, 12, 341-352. 
Copyright of Journal of Applied Communication Research is the property of National Communication Association and its content may not be copied or emailed to multiple sites or posted to a listserv without the copyright holder's express written permission. However, users may print, download, or email articles for individual use. 